\title{
Introduction to the 2019 International Conference on Social Media \& Society
}

\author{
Anatoliy Gruzd \\ Ryerson University \\ Ted Rogers School of \\ Management \\ Toronto, Canada \\ gruzd@ryerson.ca

\section{Jenna Jacobson} \\ Ryerson University \\ Ted Rogers School of Retail \\ Management \\ Toronto, Canada \\ jenna.jacobson@ryerson.ca

\section{K. Hazel Kwon} \\ Arizona State University \\ Walter Cronkite School of \\ Journalism and Mass \\ Communication \\ Arizona, USA \\ khkwon@asu.edu
}

Philip Mai

Ryerson University

Social Media Lab

Toronto, Canada

philip.mai@ryerson.ca

\section{Raquel Recuero}

Communication and Linguistics

Department

Federal University of Pelotas and Federal University of

Rio Grande do Sul, Brazil

raquelrecuero@gmail.com
Priya Kumar

Ryerson University

Social Media Lab

Toronto, Canada

p1kumar@ryerson.ca

\section{Jeff Hemsley}

Syracuse University

School of Information Studies

Syracuse, USA

jihemsle@syr.edu

\section{Anabel Quan-Haase}

Western University

Information and Media Studies and Sociology

London, Canada

aquan@uwo.ca

\section{Luke Sloan}

Cardiff University

School of Social Sciences

Cardiff, UK

sloanls@cardiff.ac.uk

\section{Jaigris Hodson}

Royal Roads University

College of Interdisciplinary Studies

Victoria, Canada

jaigris.hodson@royalroads.ca

Permission to make digital or hard copies of all or part of this work for personal or classroom use is granted without fee provided that copies are not made or distributed for profit or commercial advantage and that copies bear this notice and the full citation on the first page. Copyrights for components of this work owned by others than ACM must be honored. Abstracting with credit is permitted. To copy otherwise, or republish, to post on servers or to redistribute to lists, requires prior specific permission and/or a fee. Request permissions from Permissions@acm.org.

SMSociety '19, July 19-21, 2019, Toronto, ON, Canada

(C) 2019 Copyright is held by the owner/author(s). Publication rights licensed to ACM.

ACM 978-1-4503-6651-9/19/07...\$15.00

https://doi.org/10.1145/3328529.3328530 


\section{ABSTRACT}

This paper provides an introduction to the Proceedings of the 2019 International Conference on Social Media and Society (\#SMSociety). The conference is an annual gathering of leading social media researchers, policy makers, and practitioners from around the world. Now in its $10^{\text {th }}$ year, the 2019 conference is hosted by the Social Media Lab at the Ted Rogers School of Management at Ryerson University in Toronto, Canada. The Proceedings features a total of 26 papers (the acceptance rate is $42 \%$ ).

\section{CCS CONCEPTS}

- Human-centered computing $\rightarrow$ Social media • Information systems $\rightarrow$ World Wide Web $\rightarrow$ Web mining Information systems $\rightarrow$ World Wide Web $\rightarrow$ Web searching and information discovery $\bullet$ Information systems $\rightarrow$ World Wide Web $\rightarrow$ Web applications

\section{KEYWORDS}

Social Media Research; Social Media; SMSociety

\section{ACM Reference format:}

Anatoliy Gruzd, Philip Mai, Priya Kumar, Jenna Jacobson, Raquel Recuero, Jeff Hemsley, K. Hazel Kwon, Anabel QuanHaase, Luke Sloan, and Jaigris Hodson. 2019. Introduction to the 2019 International Conference on Social Media \& Society. In Proceedings of the International Conference on Social Media \& Society, Toronto, Canada (SMSociety).

DOI: $\underline{10.1145 / 3328529.3328530}$

\section{ABOUT THE CONFERENCE}

The International Conference on Social Media \& Society is an annual gathering of leading social media researchers, policy makers, and practitioners from around the world. Now, in its $10^{\text {th }}$ year, the 2019 conference is being held in Toronto, Canada at Ryerson University from July 19-21, 2019.

From its inception, the conference has focused on the best practices for studying the impact and implications of social media on society. Organized by Ryerson University's Social Media Lab, the conference provides participants with opportunities to exchange ideas, present original research, learn about recent and ongoing studies, and network with peers.

The conference's intensive three-day program features 2 keynote speakers, 8 workshops, 4 panels, 26 full papers, 60 work-in-progress papers, and 45 posters. The wideranging topics in social media showcase quantitative and qualitative research from scholars working in many fields including Management, Communication,
Information Science, Computer Science, Education, Journalism, Political Science, Health and Sociology.

The Proceedings include 26 published papers on various topics, including:

- Activism

- Algorithms \& Echo-Chambers

- Disasters, Outbreaks, \& Environment

- Virality \& Multimedia

- Education

- Emotions \& Well-Being

- Health

- Identity \& Community

- Influencers

- Mobile Use \& Users

- News

- Politics

- Privacy

- Security \& Anonymity

- Young People

\section{CONFERENCE THEME: RETHINKING PRIVACY AND TRUST} IN THE SOCIAL MEDIA AGE

Can we trust what we hear and see on social media? For a time, social media was viewed as a net positive for society. In their 2013 book, The New Digital Age, Google's Jared Cohen and Eric Schmidt wrote: "Never before have so many people been connected through an instantly responsive network." In 2015, Mark Zuckerberg, the cofounder and CEO of Facebook, wrote a glowing endorsement of the internet and social media calling it "a force for peace in the world." He argued that connecting people through social media would help to bring about a "shared understanding" of the human condition and build a "common global community."

Fast forward to 2019, social media is now embroiled in a series of ongoing public scandals involving data abuse and misuse-with the most infamous scandal involving the UK data analytics firm Cambridge Analytica. More troubling is the fact that social media has emerged as fertile ground for fostering anti-social behaviour [1], [2] and is an important vector for disinformation, misinformation, information and manipulation operations [3]-[5]. These realities have raised privacy concerns and challenged public trust in social media, which has resulted in a revitalized call for new legislation and regulation [6]-[9]. 
Considering this context, this year's conference asks:

- What does "privacy" and "trust" mean in the social media age?

- How does social media manipulation affect political trust and tolerance?

- How is social media being used to help build and strengthen trust in political, economic, social and cultural realms of society?

- What roles do alternative social networking services (such as Diaspora, Mastodon, and Gab.ai) play in the current social media environment where hashtag campaigns (such as \#DeleteFacebook, \#MAGA and \#MeToo) have become prevalent?

- What theoretical and methodological tools can researchers rely on for ethical and privacyprotective collection, analysis, and sharing of social media datasets?

- What are the consequences of data regulations such as GDPR (General Data Protection Regulation) on the industry and users? Are these regulations effective?

- What are emerging successful user engagement models for governments, journalists, financial institutions, marketers, and others in today's social media landscape?

- What is the future of social media research without APIs?

- How can we measure authentic (or organic) user engagement while properly accounting for botdriven (or paid) interactions?

- How does algorithmic architecture influence how we discover and interact with others?

- What role do algorithms play in creating divisive culture in social media?

- What are the ethical concerns of algorithms (such as inclusion, accessibility, discrimination, bots) and might they be mitigated?

\section{KEYNOTE ADDRESSES}

This year, we are delighted to have Tarleton Gillespie and Valerie Steeves as the keynote speakers.

Tarleton Gillespie is a principal researcher at Microsoft Research New England, and an affiliated Associate Professor in the Department of Communication and Department of Information Science at Cornell University. His new book, Custodians of the Internet: Platforms, Content Moderation, and the Hidden Decisions that Shape
Social Media (Yale University Press) was published in June 2018. He is also the author of Wired Shut: Copyright and the Shape of Digital Culture (MIT Press, 2007), the coeditor of Media Technologies: Essays on Communication, Materiality, and Society (MIT, 2014), and the co-founder of the blog Culture Digitally. Tarleton's keynote address will be on "Custodians of the Internet: Platforms, Content Moderation, and the Hidden Decisions That Shape Social Media."

Valerie Steeves is a Full Professor in the Department of Criminology at the University of Ottawa. As the lead researcher of MediaSmarts' Young Canadians in a Wired World research project, she has been tracking young people's use of new media since 2000. She is also the principal investigator of the eQuality Project, a sevenyear SSHRC-funded partnership exploring young people's experiences of privacy and equality in networked spaces. Steeves will present on "Not So Social, Not So Networked: Teens' Perspectives of Privacy and Trust on Social Media."

\section{CONFERENCE ORGANIZING COMMITTEE}

The conference is a result of the tremendous work by our Organizing Committee, Program Committee, and Advisory Board. The Organizing Committee is responsible for the organization of the annual conference, including soliciting high-quality submissions, assigning peer-reviewers, deciding on submission acceptance, developing the conference schedule, and hosting the conference. The 2019 Organizing Committee includes:

\section{Conference General Chairs}

Anatoliy Gruzd, Ryerson University, Canada

Philip Mai, Ryerson University, Canada

Priya Kumar, Ryerson University, Canada

\section{Full Papers Chairs}

Jenna Jacobson, Ryerson University, Canada

Raquel Recuero, Federal University of Pelotas and Federal University of Rio Grande do Sul, Brazil

\section{WIP Papers Chairs}

Hazel Kwon, Arizona State University, USA

Jeff Hemsley, Syracuse University, USA

\section{Panel Chairs}

Anabel Quan-Haase, Western University, Canada Luke Sloan, Cardiff University, UK

Poster Chair

Jaigris Hodson, Royal Roads University, Canada 


\section{CONFERENCE ADVISORY BOARD}

The Advisory Board is comprised of leading scholars in the field who advise the Organizing Committee on future directions of the conference, including conference themes, publication venues, and recommended keynote speakers. The 2019 Advisory Board includes:

- Caroline Haythornthwaite, Syracuse University, USA

- Susan Halford, University of Bristol, UK

- Zizi Papacharissi, University of Illinois at Chicago, USA

- Barry Wellman, NetLab Network \& Social Media Lab, Ryerson University, Canada

\section{CONFERENCE PROGRAM COMMITTEE}

The 2019 Programs Committee includes 140 scholars coming from 114 institutions and 26 countries who rigorously conduct and oversee the peer review process for all full and WIP papers (either by doing double blind reviews themselves or assigning sub-reviewers). We are delighted to have diverse disciplinary and methodological perspectives on the committee. For a full list of the conference program committee members see: https://socialmediaandsociety.org/about

\section{ACKNOWLEDGMENTS}

We would like to thank all of the contributing authors and peer reviewers who ensured the high quality of papers at the conference. We would also like to thank Andrea Kampen and Carlisle Kent for their editorial assistance in preparing the Proceedings, Hanako Smith for being a Volunteer Coordinator, and Alicia Wanless for being the conference Social Media Ambassador. Finally, we thank the Ted Rogers School of Management for hosting the conference.

\section{REFERENCES}

[1] I. Chaudhry and A. Gruzd, "Expressing and Challenging Racist Discourse on Facebook: How Social Media Weaken the 'Spiral of Silence' Theory," Policy \& Internet.

[2] J. Hemsley, J. Jacobson, A. Gruzd, and P. Mai, "Social Media for Social Good or Evil: An Introduction," Social Media + Society, vol. 4, no. 3, p. 2056305118786719 , Jul. 2018.

[3] R. Recuero, A. Gruzd, R. Recuero, and A. Gruzd, "Cascatas de Fake News Políticas: um estudo de caso no Twitter," Galáxia (São Paulo), no. 41, pp. 31-47, Aug. 2019.
[4] M. E. D. Valle, A. Wanless-Berk, A. Gruzd, and P. Mai, "Click, Therefore I Am: Predicting Clicktivist-Like Actions on Candidates? Facebook Posts During the 2016 US Primary Election," in Networks, Hacking, and Media?CITA MS@30: Now and Then and Tomorrow, vol. 17, 0 vols., Emerald Publishing Limited, 2018, pp. 137-154.

[5] M. Y.-J. Song and A. Gruzd, "Examining Sentiments and Popularity of Pro- and Anti-Vaccination Videos on YouTube," in Proceedings of the 8th International Conference on Social Media \& Society, New York, NY, USA, 2017, pp. 1-8.

[6] J. Jacobson, A. Gruzd, and Á. Hernández-García, "Social media marketing: Who is watching the watchers?" Journal of Retailing and Consumer Services, Mar. 2019.

[7] A. Gruzd, J. Jacobson, P. Mai, and E. Dubois, "Social Media Privacy in Canada." Ryerson University Social Media Lab. DOI: https://doi.org/10.5683/SP/JVOT0S.

[8] A. Gruzd and Â. Hernández-García, "Privacy Concerns and Self-Disclosure in Private and Public Uses of Social Media," Cyberpsychology, Behavior, and Social Networking, vol. 21, no. 7, pp. 418-428, Jul. 2018.

[9] E. Dubois, A. Gruzd, and J. Jacobson, “Journalists' Use of Social Media to Infer Public Opinion: The Citizens' Perspective," Social Science Computer Review, p. 0894439318791527, Aug. 2018. 